\title{
Morphological studies of honey bees in the northern wooded steppe zone of the Republic of Bashkortostan
}

\author{
Milyausha $R$. Sobirjonova ${ }^{1, *}$, Natalia Ye. Zemskova ${ }^{2}$, Vener N. Sattarov ${ }^{1}$ and Roman V. Mishchuk ${ }^{1}$ \\ ${ }^{1}$ Bashkir State Pedagogical University n.a. M. Akmulla, department of natural science and geography, Ufa, 450008, Russia \\ ${ }^{2}$ Samara State Agrarian University, Department of biotechnology and veterinary medicine, Ust-Kinelskiy, 446442, Samarskaya oblast, \\ Russia
}

\begin{abstract}
The article presents assessment results for the preservation of European dark honey bees in the northern wooded steppe zone of the Republic of Bashkortostan, which is an integral structure in the honey bee Apis mellifera mellifera population of northern Bashkortostan. Bee farms of 24 settlements in Askinskiy, Arkhangelskiy, Baltachevskiy, Karaidelskiy and Yanaulskiy districts show the persistence of taxonomically pure bees, which stands for $73 \%$ of the samples. During the bee-breed identification, the most volatile parameters were determined (the length the rostrum, the length and width of the right hemelytron, the cubital index) that are greatly influenced by the hybridization processes. The presence of registered pure-breed bee colonies speaks of the biopotential of the European dark bee population in the farms of the given region, which will allow to create pedigree breeding units and pure breeding zones for native bees in the future.
\end{abstract}

\section{Introduction}

The breeding work on bee farms of any levels nowadays is mostly connected with increasing the productivity of bee colonies by producing and using hybrid bees. The scientific validity of this method is beyond questioning, as well as the use of the heterosis effect that allows to significantly increase the productivity of colonies if good cross-breed combinations are found. The success of such activities depends on access to biologically pure materials [1-4].

Konusova O. L. et al pointed out that the main goal of bee-keeping is the increase of productivity of colonies, which is mainly characterized by winter hardiness, melliferous capacity, and the productivity of the queens. To achieve this goal, it is crucial to have a biological and economic assessment of bees, finding the pure breed colonies, and producing highly-fertile queens [5].

The importance of preserving pure-breed bees was noted by V.A. Gubin, who wrote in one of his works (1984): "under the conditions of uncontrolled mating at bee farms surrounded by colonies of different or unknown breeds, which is often the case, the question of practical usage of the heterosis effect is not easy and obvious" [6]. The author also claimed that it must be kept in mind that cross-breed hybrid may often have 'inferior parameters' [6].

At the same time, N.V. Ostroverkhova et al claim that the genetic diversity typical of natural populations is one of the most important conditions for the sustainable development of bee farming [7]. Currently, the global loss of diversity and numbers of bees is evident all over the world, therefore one of the key objectives of beekeeping must be the preservation of native breeds and populations of the honey bee.

Within the Republic of Bashkortostan (RB), according to some researchers, several populations are preserved in Tatyshly, Aksino and Baltachevo apart from the Burzyan population, which all put together can comprise the north Bashkir population of Apis mellifera mellifera [8, 9]. Taking into consideration that the processes of global hybridization and pure-breed population disappearance take place in all of the regions, the research aimed at preservation monitoring is of the highest scientific and practical significance.

\section{Materials and Methods}

The study objects are the imagos of honey bees workers (Fig. 1).

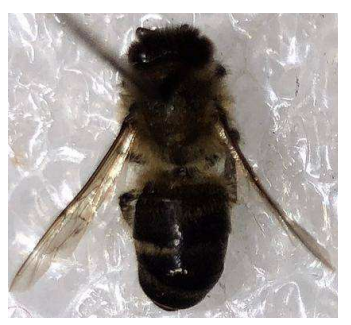

Fig. 1. Worker honey bee specimen

\footnotetext{
* Corresponding author: nurkaeva88@bk.ru
} 


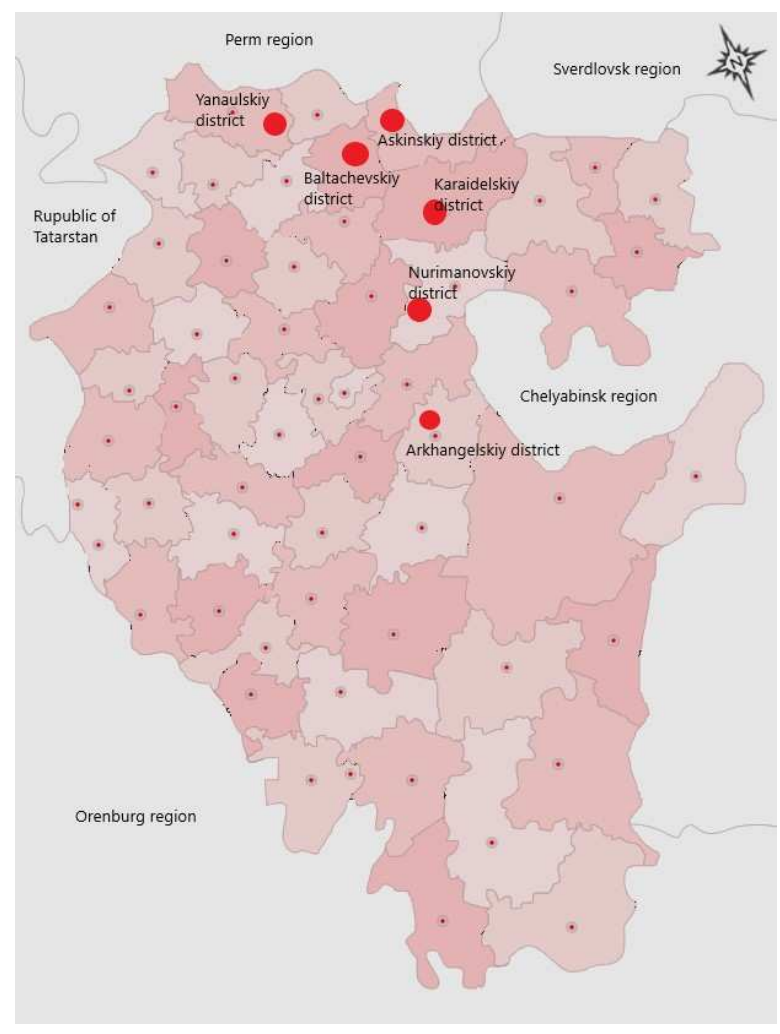

Fig. 2. The map of Bashkortostan (sampling locations are marked in red)

The field research (2010-2018) was carried out in bee farms in administrative districts of the northern wooded steppe zone of the Republic of Bashkortostan: Askinskiy, Arkhangelskiy, Baltachevskiy, Karaidelskiy, Nurimanovskiy and Yanaulskiy (Fig. 2). The total of bee colonies (farms/settlements) was 1300 per 28 settlements. We used a standard morphometric method for the assessment of worker bees.

The data obtained were compared with the established European standards from the literature [10]. To analyze the consolidated data, we used the Statistica software version 6.1 .

\section{Results and Discussion}

The results of the morphological study of worker honey bees (Apis mellifera) from the northern wooded steppe zone of Bashkortostan are presented in Table 1.

In Askinskiy district, samples were taken from farms in five settlements: Askino (40 farms/settlement), Kuchanovo (60 farms/settlement), Matala (50 farms/ settlement, Kayumovo (50 farms/settlement) and Stepanovka (50 farms/settlement). The total of colonies is 250. The bees complied with the standard of Apis mellifera mellifera in almost all parameters. For example, the average rostrum lengths in $\mathrm{mm}$ were: (6.19 \pm 0.14 (Askino), 6.16 \pm 0.14 (Kuchanovo), 6.22 \pm 0.09 (Matala), $6.23 \pm 0.09$ (Kayumovo and Stepanovka)) did not exceed or fall under the standard limits $(6.0-6.4 \mathrm{~mm})$. The same situation was with the upper and lower limit

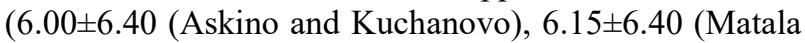
and Kayumovo), 6.10 \pm 6.40 (Stepanovka)).

Table 1. The results of the morphological study of Apis mellifera from the farms in the northern wooded steppe zone of Bashkortostan

\begin{tabular}{|c|c|c|c|c|c|c|c|}
\hline \multirow{2}{*}{ Parameter } & \multirow{2}{*}{$\begin{array}{l}\text { *Indic } \\
\text { ator }\end{array}$} & \multicolumn{6}{|c|}{ District and morphological measurement results } \\
\hline & & Askinskiy & Arkhengelskiy & Baltachevskiy & Karaidelskiy & Nurimanovskiy & Yanaulskiy \\
\hline \multirow{2}{*}{$\begin{array}{l}\text { Length of } \\
\text { rostrum, mm }\end{array}$} & $M \pm m$ & $6.2 \pm 0.1$ & $6.2 \pm 0.1$ & $6.2 \pm 0.1$ & $6.2 \pm 0.1$ & $6.7 \pm 0.3$ & $6.2 \pm 0.1$ \\
\hline & lim & $6.0-6.4$ & $6.0-6.4$ & $5.9-6.4$ & $6.0-6.4$ & $6.3-7.1$ & $6.0-6.4$ \\
\hline \multirow{2}{*}{$\begin{array}{l}\text { Length of right } \\
\text { hemelytron, mm }\end{array}$} & $M \pm m$ & $9.3 \pm 0.1$ & $9.3 \pm 0.1$ & $9.3 \pm 0.1$ & $9.3 \pm 0.2$ & $8.9 \pm 0.1$ & $9.4 \pm 0.2$ \\
\hline & $\lim$ & $9.0-9.6$ & $9.0-10.0$ & $9.2-10.0$ & $9.0-10.0$ & $8.7-10.0$ & $9.2-10.1$ \\
\hline \multirow{2}{*}{$\begin{array}{c}\text { Width of right } \\
\text { hemelytron, mm }\end{array}$} & $M \pm m$ & $3.1 \pm 0.1$ & $3.2 \pm 0.1$ & $3.1 \pm 0.1$ & $3.2 \pm 0.1$ & $3.1 \pm 0.1$ & $3.1 \pm 0.2$ \\
\hline & lim & $3.0-3.5$ & $3.0-3.5$ & $3.0-3.5$ & $3.0-3.5$ & $2.7-3.5$ & $3.0-3.5$ \\
\hline \multirow{2}{*}{$\begin{array}{c}\text { Cubital } \\
\text { index, \% }\end{array}$} & $M \pm m$ & $63.4 \pm 0.1$ & $63.4 \pm 0.9$ & $63.5 \pm 0.8$ & $63.5 \pm 0.8$ & $59.6 \pm 2.8$ & $63.6 \pm 0.9$ \\
\hline & $\lim$ & $60.0-65.0$ & $60.0-65.0$ & $60.0-65.0$ & $61.4-65.0$ & $53.5-65.4$ & $60.0-65.0$ \\
\hline \multirow{2}{*}{$\begin{array}{l}\text { Length of } 4 \text { th dorsal } \\
\text { plate, } \mathrm{mm}\end{array}$} & $M \pm m$ & $2.3 \pm 0.1$ & $2.3 \pm 0.1$ & $2.4 \pm 0.1$ & $2.3 \pm 0.1$ & $2.3 \pm 0.1$ & $2.4 \pm 0.1$ \\
\hline & lim & $2.3-2.5$ & $2.3-2.5$ & $2.3-2.5$ & $2.3-2.5$ & $2.1-2.6$ & $2.3-2.6$ \\
\hline \multirow{2}{*}{$\begin{array}{c}\text { Width of } 4 \text { th } \\
\text { dorsal plate, } \mathrm{mm}\end{array}$} & $M \pm m$ & $4.9 \pm 0.1$ & $4.8 \pm 0.1$ & $4.8 \pm 0.1$ & $4.8 \pm 0.1$ & $4.8 \pm 0.1$ & $4.8 \pm 0.1$ \\
\hline & $\lim$ & $4.8-4.9$ & $4.8-4.9$ & $4.8-5.0$ & $4.8-5.0$ & $4.6-4.9$ & $4.8-5.0$ \\
\hline \multirow{2}{*}{$\begin{array}{l}\text { Length of } 4 \text { th sternum, } \\
\text { mm }\end{array}$} & $M \pm m$ & $3.1 \pm 0.1$ & $3.1 \pm 0.1$ & $3.1 \pm 0.1$ & $3.1 \pm 0.1$ & $3.1 \pm 0.1$ & $3.1 \pm 0.1$ \\
\hline & $\lim$ & $3.1-3.2$ & $3.1-3.3$ & $3.0-3.2$ & $3.0-3.2$ & $2.9-3.2$ & $3.0-3.2$ \\
\hline \multirow{2}{*}{$\begin{array}{c}\text { Width of 4th } \\
\text { sternum, mm }\end{array}$} & $M \pm m$ & $4.8 \pm 0.1$ & $4.8 \pm 0.1$ & $4.8 \pm 0.1$ & $4.8 \pm 0.1$ & $3.9 \pm 0.1$ & $4.8 \pm 0.1$ \\
\hline & lim & $4.8-4.9$ & $4.8-4.9$ & $4.7-4.9$ & $4.6-4.9$ & $3.9-4.1$ & $4.7-4.9$ \\
\hline \multirow{2}{*}{$\begin{array}{l}\text { Length of wax } \\
\text { plate, } \mathrm{mm}\end{array}$} & $M \pm m$ & $2.6 \pm 0.1$ & $2,6 \pm 0,1$ & $2.6 \pm 0.1$ & $2.6 \pm 0.1$ & $2.5 \pm 0.1$ & $2.6 \pm 0.1$ \\
\hline & $\mathrm{lim}$ & $2.5-2.7$ & $2.5-2.7$ & $2.5-2.7$ & $2.5-2.7$ & $2.4-2.8$ & $2.5-2.7$ \\
\hline \multirow{2}{*}{$\begin{array}{c}\text { Width of } \\
\text { wax plate, } \mathrm{mm}\end{array}$} & $M \pm m$ & $1.6 \pm 0.1$ & $1.6 \pm 0.1$ & $1.6 \pm 0.1$ & $1.6 \pm 0.1$ & $1.5 \pm 0.1$ & $1.6 \pm 0.0$ \\
\hline & lim & $1.5-1.6$ & $1.5-1.7$ & $1.5-1.6$ & $1.5-1.7$ & $1.4-1.7$ & $1.5-1.7$ \\
\hline \multirow{2}{*}{$\begin{array}{c}\text { Tarsal } \\
\text { index, \% }\end{array}$} & $M \pm m$ & $53.1 \pm 0.7$ & $53.1 \pm 0.7$ & $53.1 \pm 0.7$ & $53.1 \pm 0.9$ & $53.9 \pm 2.7$ & $53.4 \pm 0.8$ \\
\hline & $\lim$ & $52.4-54.6$ & $52.4-54.6$ & $50.4-54.6$ & $50.4-54.6$ & $49.3-59.6$ & $50.7-55.0$ \\
\hline
\end{tabular}

*Note. The table shows values rounded to a tenth, and further in the text values are rounded up to a hundredth.

The same situation was with the length and width of the hemelytron. The standard values for the European dark bee are 9-10 $\mathrm{mm}$ (length), 3-3.5 $\mathrm{mm}$ (width). The average lengths obtained are $9.32 \pm 0.06$ (Askino), 9.32 \pm 0.05 (Kuchanovo), 9.31 \pm 0.06 (Matala), 9.31 \pm 0.06 (Kayumovo), 9.31 \pm 0.05 (Stepanovka); the limit values: 
9.30-9.60 (Askino, Kuchanovo, and Stepanovka), limit 9.00-9.50 mm (Matala and Kayumovo). The average values for width are as follows: $3.13 \pm 0.12$ (Askino), $3.12 \pm 0.11$ (Kuchanovo), 3.16 \pm 0.09 (Matala), 3.15 \pm 0.09 (Kayumovo) and $3.14 \pm 0.11$ (Stepanovka). The cubital index also complied with the standard - 60-65\%. Its averages were as follows: 63.42 \pm 0.98 (Askino), 63.52 $\pm 0.91 \quad$ (Kuchanovo), 63.51 $\pm 0.85 \quad$ (Matala), $63.51 \pm 0.85$ (Kayumovo) and 63.46 \pm 0.99 (Stepanovka). The next parameter is the dorsal plate. Its parameters complied with the European dark bee standard (length of 2.30-2.60 mm, width of $4.80-5.00 \mathrm{~mm}$ ). The average dorsal plate length and width values (in $\mathrm{mm}$ ) were as follows: $2.37 \pm 0.08$ and $4.86 \pm 0.05$ (Askino), $2.36 \pm 0.08$, $4.86 \pm 0.04$ (Kuchanovo), $2.36 \pm 0.07$ and $4.86 \pm 0.04$ (Matala), $2.36 \pm 0.07$ and $4.85 \pm 0.05$ (Kayumovo) and $2.36 \pm 0.770,4.86 \pm 0.05$ (Stepanovka). The limit values for length and width (in $\mathrm{mm}$ ) also remained within the standard: $2.36-2.55$ and 4.82-4.96 (Askino); 2.30-2.55, 4.82-4.96 (Kuchanovo); 2.30-2.50, 4.82-4.96 (Matala); 2.30-2.50 and 4.81-4.96 (Kayumovo) and 2.30-2.55, 4.82-4.96 (Stepanovka). The sternum values also complied with the standard (3-3.20 mm length, 4.75$4.90 \mathrm{~mm}$ width). For example, in Askino, the length was $3.14 \pm 0.06$, limit - 3.02-3.19, and the width was $4.81 \pm 0.06$, limit 4.75-4.90; In Kuchanovo 3.13 $\pm 0,06$, limit 3.02-3.19; and 4.81 \pm 0.05 , limit 4.76-4.85 respectively; in Matala, 3.13 \pm 0.06 , limit 3.02-3.18 and

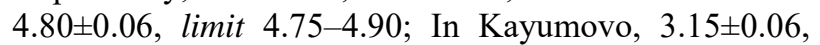
limit 3.03-3.17 and 4.80 \pm 0.05 , limit 4.75-4.90; in Stepanovka 3.16 \pm 0.01 , limit $3.04-3.19$ and $4.81 \pm 0.05$ respectively. The next parameter is the wax plate (standard length of $2.45-2.70 \mathrm{~mm}$ and width of $1.50-1.70 \mathrm{~mm}$ ). These values did not exceed or fall below the standard limits. The last parameter analyzed is the tarsal index. In this respect, the bees also complied with the standard for the European dark bee breed (50-55 \%): in Askino, the average was $53.07 \pm 0.71$ (limit 53.39-54.57), in Kuchanovo, 53.07 \pm 0.708 (limit 52.39-54.56), in Matala, $53.09 \pm 0.745$ (limit 52.38-54.56), in Kayumovo, $53.08 \pm 0.73$ (limit 52.40-54.56) and in Stepanovka, $53.90 \pm 0.73$ (limit 52.52-54.57) respectively.

In Arkhangelskiy district, bees were sampled for analysis from four settlements: Terekly (50 farms/settlement), Aytmembetovo (50 farms/settlement), Askino (50 farms/settlement) and Bakaldinskoye (50 farms/settlement). The results show the presence of the European dark bee breed. We got the following data on the average and limit lengths of rostrum (in $\mathrm{mm}$ ): Terekly 6.22 \pm 0.06 (limit 6.10-6.30); Aytmembetovo 6.21-0.07 (limit 6.00-6.30), Askino 6.21-0.07 (limit 6.00-6.40), Bakaldinskoye 6.20 \pm 0.14 (limit 6.00-6.40). The averages of the cubital index in \% also complied with the standard: 63.46 \pm 0.93 (Terekly), 63.45 \pm 0.93 (Aytmembetovo), 63.38 \pm 0.89 (Askino), 63.65 \pm 0.98 (Bakaldinskoye). The same situation is observed for other parameters as well.

In Baltachevskiy district, the sampling was carried out on bee farms in six settlements: Starobaltachevo (35 farms/settlement), Kundashly (45 farms/settlement), Mishkino (30 farms/settlement), Seytyakovo
(30 farms/settlement), Norkino (30 farms/settlement) and Annovka (30 farms/settlement). The bees complied with the European dark bee standard in all parameters. On the farms of Seytyakovo, there were bees whose parameters exceeded the limit values of the standard in rostrum length (standard of 6-6.4 mm). Despite this, the bees from this settlement can be deemed as European dark bees because may authors claim that the rostrum length standard for this breed is $5.95-5.50 \mathrm{~mm}$, and all the other parameters were in compliance with the standard.

In Karaidelskiy district, the sampling was carried out on bee farms in the following settlements: Baykirashevo (60 farms/settlement), Karaidel (50 farms/settlement), Suleymanovo (40 farms/settlement) and Yavgildino (50 farms/settlement). The average rostrum length ( $\mathrm{mm})$ is as follows: $6.25 \pm 0.09$ (Baykirashevo), $6.24 \pm 0.08$ (Karaidel), 6.23 \pm 0.07 (Suleymanovo), $6.24 \pm 0.08$ (Yavgildino). The situation with the length and width of hemelytron is identical. The average length $(\mathrm{mm})$ is as follows: $\quad 9.32 \pm 0.02 \quad$ (Baykirashevo), $9.35 \pm 0.16$ (Karaidel), $\quad 9.36 \pm 0.15 \quad$ (Suleymanovo), $\quad 9.34 \pm 0.12$ (Yavgildino); and the limit is 9.00-10.00 (Baykirashevo and Karaidel), 9.10-9.90 (Suleymanovo) and 9.30-10.00 (Yavgildino). The average hemelytron width $(\mathrm{mm})$ is as follows: $\quad 3.17 \pm 0.12$ (Baykirashevo), $3.17 \pm 0.11$ (Karaidel), $3.18 \pm 0.11 \quad$ (Suleymanovo), $3.18 \pm 0.12$ (Yavgildino).

The cubital index also complied with the standard (in $\begin{array}{lll}\mathrm{mm}): & 63.46 \pm 0.91 \quad \text { (Baykirashevo), } & 63.54 \pm 0.88\end{array}$ (Karaidel), $63.48 \pm 0.75$ (Suleymanovo), $63.50 \pm 0.90$ (Yavgildino). The limit values of the index also complied with the standard. The dorsal plate parameters were fully compliant with the European dark bee standard (in $\mathrm{mm}$ ): $2.37 \pm 0.08$ and $4.87 \pm 0.05$ (Baykirashevo), $\quad 2.36 \pm 0.08, \quad 4.87 \pm 0.05 \quad$ (Karaidel), $2.39 \pm 0.06$ and $4.89 \pm 0.06$ (Suleymanovo), $2.39 \pm 0.06$ and $4.87 \pm 0.05$ (Yavgildino). The situation with the sternum and the wax plate was identical. For example, wax plate parameters (in mm): Baykirashevo: length $3.13 \pm 0.07$, limit - 3.02-3.19, width 4.79 \pm 0.05 , limit 4.75-4.90; Karaidel: $3.14 \pm 0.06$, limit $3.02-3.19$; and $4.80 \pm 0.05$, limit 4.75-4.90; Suleymanovo: $3.11 \pm 0.074$, limit 3.00-3.19; and 4.82 \pm 0.05 , limit 4.75-4.90; Yavgildino: $3.14 \pm 0.06$, limit 3.00-3.19; and $4.80 \pm 0.055$, limit 4.75-4.90 respectively. The tarsal index of the bees also complies with the breed standard: in Bayrikashevo, the average was $53.22 \pm 0.77 \%$ (limit 52.52-54.57), in Karaidel $53.15 \pm 0.72 \%$ (limit 52.52-54.43), in Suleymanovo $53.14 \pm 0.96 \%$ (limit 50.36-54.43), and in Yavgildino $\quad 53.09 \pm 0.92 \quad \% \quad$ (limit 51.55-54.57) respectively.

In Nurimanoskiy district, samples were taken from 250 farms from four settlements: Nikolskoye, Novokulevo, Urman and Novoisayevo. In this district, hybridization processes were detected. For example, the rostrum lengths were as follows (in $\mathrm{mm}$ ): $6.73 \pm 0.22$, with the limit value of $6.50-7.00$ (Nikolskoye), $6.71 \pm 0.26$, with the limit of 6.30-7.10 (Novokulevo), $6.74 \pm 0.25$ (limit 6.30-7.00) (Urman), 6.68 \pm 0.26 limit 6.40-7.10) (Novoisayevo). As we can see, the average values exceed the standard of Apis mellifera mellifera. 
However, the lower limit values for bees from Novokulevo, Novoisayevo, and Urman comply with the standard of the European dark bee, while the upper limit is beyond its requirements. In Nikolskoye, the limit values of bees are not compliant with the breed standard. The hemelytron length and width values in two of the farms did not comply with the breed standard (in $\mathrm{mm}$ ): Novokulevo (8.99 \pm 0.10$)$ and Novoisayevo (8.98 \pm 0.08$)$, and in two others, they did: Nikolskoye $(9.00 \pm 0.09)$ and Urman $(9.02 \pm 0.17)$. The average hemelytron width were in compliance with the European dark bee standard (3.13 \pm 0.15 -in Nikolskoye, $3.14 \pm 0.12$ in Novokulevo, $3.13 \pm 0.15$ in Urman, $3.17 \pm 0.12$ in Novoisayevo). The situation with the cubital index was identical. For instance, the averages exceeded the standard requirements (in \%): $59.71 \pm 2.74$ (Nikolskoye), $59.80 \pm 2.72 \quad$ (Novokulevo), 59.18 $\pm 2.92 \quad$ (Urman), $59.89 \pm 2.98$ (Novoisayevo). The results of dorsal plate measurement are also controversial. Here, the average values for bees from three farms were compliant with the standard (in mm): Nikolskoye - 2.31 \pm 0.09 ; Novokulevo

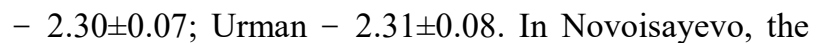
dorsal plate length was below the standard for the European dark bee: $2.28 \pm 0.052$. The limit values for dorsal plate length were also controversial: the lower limit value was always below the standard: Nikolskoye 2.16-2.65 mm; Novokulevo - 2.16-2.55 mm; Urman 2.10-2.55 mm; Novoisayevo - 2.21-2.40 mm, and the upper one was in compliance with the breed standard. Let us look at the dorsal plate width. In Novoisayevo, the average value and the lower limit were below the standard: $4.79 \pm 0.08 \mathrm{~mm}$ and $4.65-4.96 \mathrm{~mm}$ respectively. In the rest of the settlement, the average values complied with the established standard (in $\mathrm{mm}$ ): Nikolskoye $4.81 \pm 0.08$, Novokulevo 4.81 \pm 0.08 , Urman $-4.81 \pm 0.08$. The average sternum lengths complied with the Apis mellifera mellifera (in mm): Nikolskoye - 3.10 \pm 0.08 ; Novokulevo - 3.11 \pm 0.08 ; Urman - 3.10 \pm 0.08 ; Novoisayevo - 3.11 \pm 0.083 . The limit values were compliant in one farm only: Nikolskoye $-3.00-3.20 \mathrm{~mm}$. On other farms, the lower limit did not comply with the standard: Novokulevo - 2.99-3.20 mm, Urman 2.99-3.22 mm, Novoisayevo - 2.99-3.21 mm. The sternum width did not comply with the standard at all. The results of wax plate measurement were also controversial. With the standard range of $1.50-1.70 \mathrm{~mm}$, we got the following data: Nikolskoye $(1.54 \pm 0,08)$, Novokulevo (1.54 $\pm 0,07)$, Urman (1.54 \pm 0.07$)$, Novoisayevo (1.56 \pm 0.07$)$. The analysis of limit values for the wax plate showed that the lower limits were below the standard, while the upper limits complied with it, except for the bee farm in Nikolskoye: Nikolskoye (1.41-1.72 mm), Novokulevo (1.39-1.67 mm), Urman $(1.40-1.65 \mathrm{~mm})$, Novoisayevo $(1.43-1.66 \mathrm{~mm})$. The results for the wax plate width were identical. The tarsal index averages comply with the standard, but its limit values showed the presence of a different breed, i.e. the lower and the upper values were outside the standard requirements: $\quad 49.52-59.02 \%, \quad 49.52-59.59 \%$, 49.51-59.59, 49.27-58.82\%.

In Yanaulskiy district, the sampling was carried out in the following settlements: Bayguzino, Isanbayevo, Yambiyevo, Akhtiyal, and Sandugach. The total of colonies is 200. The bees complied with the breed standard in all parameters. The average rostrum lengths (in $\mathrm{mm}$ ) is as follows: Bayguzino - 6.16 \pm 0.16 ; Isanbayevo - 6.27 \pm 0.08 ; Yambayevo - 6.26 \pm 0.07 ; Akhtiyal - 6.25 \pm 0.12 ; Sandugach - 6.27 \pm 0.07 . The hemelytron length averages were within the following ranges (in mm): 9.44 \pm 0.24 (Bayguzino), 9.44 \pm 0.23 (Isanbayevo), 9.41 \pm 0.17 (Yambayevo), $9.46 \pm 0.25$ (Akhtiyal), 9.43 \pm 0.21 (Sandugach). The hemelytron width averages (in $\mathrm{mm}$ ) were as follows: $3.19 \pm 0.18$ (Bayguzino), $3.20 \pm 0.13 \quad$ (Isanbayevo), $3.18 \pm 0.17$ (Yambayevo), 3.13 \pm 0.15 (Akhtiyal) and $3.21 \pm 0.140$ (Sandugach). The cubital index in \%: 63.66 \pm 1.02 (Bayguzino), 63.70 \pm 0.89 (Isanbayevo), 63.69 \pm 0.79 (Yambayevo), 63,46 \pm 1.09 (Akhtiyal) and 63.68 \pm 0.82 (Sandugach). The next tested parameter is the dorsal plate. Its values fully complied with the standard of the European dark bee breed. The average length and width (in $\mathrm{mm}$ ) were as follows: $2.37 \pm 0.08$ and $4.86 \pm 0.04$ (Bayguzino), 2.44 $\pm 0.07, \quad 4.90 \pm 0.06 \quad$ (Isanbayevo), $2.44 \pm 0.07$ and $4.90 \pm 0.06$ (Yambayevo), $2.44 \pm 0.07$ and $4.89 \pm 0.06$ (Akhtiyal) and $2.43 \pm 0.07, \quad 4.89 \pm 0.05$ (Sandugach). The sternum (in $\mathrm{mm}$ ): Bayguzino: length $3.14 \pm 0.06$, limit - 3.02-3.19, width $4.81 \pm 0.06$, limit 4.75-4.90; Isanbayevo: 3.14 \pm 0.07 , limit 3.00-3.20; and 4.83 \pm 0.05 , limit 4.76-4.95; Yambayevo: $3.14 \pm 0.05$, limit 3.05-3.20; and 4.84 \pm 0.05 , limit 4.77-4.95; Akhtiyal: $3.13 \pm 0.05$, limit $3.02-3.19$; and $4.82 \pm 0.06$, limit 4.75-4.90; Sandugach: $3.14 \pm 0.05$, limit $3.05-3.20$ and $4.83 \pm 0.05,4.77-4.95$ respectively. The wax plate, $\mathrm{mm}$ : Bayguzino: $1.56 \pm 0.03$ (limit 1.53-1.61), 2.58 \pm 0.07 (limit 2.50-2.70); Isanbayevo: $1.56 \pm 0.03$ (limit 1.50-1.65), $2.59 \pm 0.07$ (limit 2.52-2.70); Yambayevo: $1.56 \pm 0.03$ (limit 1.54-1.65), 2.60 \pm 0.06 (limit 2.54-2.70); Akhtiyal: $1.55 \pm 0.025 \quad$ (limit $1.55-1.60), \quad 2.60 \pm 0.06 \quad$ (limit 2.53-2.69); Sandugach: $1.57 \pm 0.03$ (1.53-1.6), 2.61 \pm 0.07 (limit 2.50-2.70). The tarsal index in \%: in Bayguzino the average was $53.07 \pm 0.72$ (limit 52.39-54.57), in Isanbayevo $53.23 \pm 0.85$ (limit 51.16-54.75), in Yambayevo 53.21 \pm 0.863 (limit 50.70-54.50), in Akhtiyal 53.10 \pm 0.80 (limit 51.00-53.55), in Sandugach $54.22 \pm 0.72$ (limit 52.10-54.20) respectively.

All in all, the European dark bee was registered on 24 bee farms in the following settlements: Askinskiy district: Askino, Kuchanovo, Matala, Kayumovo, Stepanovka; Arkhangelskiy district: Terekly, Aytmembetovo, Askino, and Bakaldinskoye; Baltachevskiy district: Starobaltachevo, Kundashly, Mishkino, Seytyakovo, Norkino, and Annovka; Karaidelskiy district: Baykirashevo, Karaidel, Suleymanovo, Yavgildino, Yanaulskiy district: Bayguzino, Isanbayevo, Yambayevo, Akhtiyal, and Sandugach. In Nurimanovskiy district, hybrid bees were detected in Nikolskoye, Kovokulevo, Urman, and Novoisayevo. It is also worth noting that during the honey bee breed identification, the most volatile 
parameters were determined (the length the rostrum, the length and width of the right hemelytron, the cubital index) that are, in our opinion, greatly influenced by the hybridization processes. Among the key factors for these biological phenomena are, first of all, a lasting expansion of new breeds and breed groups, as well as the lack of scientifically grounded selection and breeding activities both on particular bee farms and in the wooded steppe zone of Bashkortostan in general. However, the presence of pure-breed bee colonies signifies that the European dark bee population in this region has certain biopotential.

\section{Conclusion}

It is well known that local adaptations of honey bees are unique and conservative. However, some actions that do not take into consideration the standpoint of population biology lead to the disappearance of native populations, which is true about the Bashkir honey bee population. The research carried out in the northern part of RB shows that $950(73 \%)$ of the bee colonies out of 1300 belong to the European dark bee, which proves the presence of the local population in the area which used to belong to the mountain and forest ecotype. We believe that the domination of the European dark bee is due to the reserve in Tatyshlinskiy district and the areas bordering the Perm region, the low amount of agricultural lands, the presence of lime trees, and the closeness of Birskiy and Askinskiy wildlife sanctuaries that perform some environmental activities.

In the future, the creation of breeding farms will allow for the replenishment of pedigree material for amateur and professional bee farms, and it will be the first step in the transition to the pure-breeding. That being said, the next step is the creation of the 'pure' breeding area in the northern part of $\mathrm{RB}$, and a key instrument in this respect is setting up drone barriers with respect to the protected breed.

\section{References}

1. N.M. Abdulgazina, M.F. Abdullin, M.V. Bakalova et al., Forest dark bee Apis mellifera mellifera L., Monograph (KMK Publ. Huse, Moscow, 2016), pp. 20-25

2. M.D. Yeskova, The biological bases of bee farming, study guide (RGAZU, Moscow, 2010), 175 p.

3. N.E. Zemskova N.E., V.N. Sattarov, A.I. Skvortsov, V.G. Semenov, Morphological characteristics of honey bees of the Volga region, BIO Web Conf., 17 (2020)

4. N.R. Gazizova, Ch.R. Galiyeva, V.R. Tuktarov, The comprehensive morphological assessment of Apis mellifera drones in the Southern Urals, Bull. of Bashkir State Agrar. Univer., 2(50), 65-71 (2019)

5. O.L. Konusova, Yu.L. Pogorelov, N.V. Ostroverkhova, S.A. Rasseykin et al., The biological and economic assessment of the honey bee (Apis mellifera L.) colonies in several districts of Tomskaya oblast, Tomsk State Univer. J., Biol., 1(9), 29-41 (2010)

6. V.A. Gubin, Pure breed bees as the basis of stock breeding on a bee farm, Beekeep., 3, 24-25 (1984)

7. N.V. Ostroverkhova, S.A. Rosseykina, O.L. Konusova, A.N. Kucher, T.N. Kireyeva, The diversity of the honey bee Apis mellifera $L$. in Tomskaya oblast as evident by morphometric and molecular genetic markers, Tomsk State Univer. J., Biol., 47, 142-173 (2019)

8. R.A. Ilyasov, A.V. Poskryakov, A.V. Petukhov, A.G. Nikolenko, The analysis of the genetic pool state of the nowadays population of the forest dark bee Apis mellifera mellifera in the Urals and the Volga region, Biomics, 7(3), 167-191 (2015)

9. R.A. Ilyasov, A.V. Petukhov, A.V. Poskryakov, A.G. Nikolenko, Local populations of Apis mellifera mellifera L. in the Urals, Russ. J. of Gener., 43(6), 855-858 (2007)

10. F. Ruttner, Breeding and selection techniques for bees: a practical guide (ACT: Astrel, Moscow, 2006), pp. 126-159 